\title{
Solar-thermal heating potential in the UK: A techno-economic whole-energy system analysis
}

\author{
Matthias Mersch ${ }^{a, b, c}$, Andreas V. Olympios ${ }^{a, c}$, Paul Sapin $^{a}$, Niall Mac Dowell ${ }^{b, c}$ and \\ Christos N. Markides ${ }^{a, c}$ \\ a Clean Energy Processes (CEP) Laboratory, Department of Chemical Engineering, Imperial \\ College London, London, UK, c.markides@imperial.ac.uk (CA) \\ ${ }^{b}$ Centre for Environmental Policy (CEP), Imperial College London, London, UK \\ ${ }^{c}$ Centre for Process Systems Engineering (CPSE), Department of Chemical Engineering, \\ Imperial College London, London, UK
}

\begin{abstract}
:
We investigate the potential of solar-thermal collectors as a sustainable heat-generation technology in the UK. The costs and performance of commercially-available collectors are surveyed and four representative collectors are investigated using a techno-economic model of solar heating for households. A parametric study of different collectors and storage tank sizes is conducted to assess the potential and economics of different system layouts. It is shown that moderately-sized systems with a collector area of $4 \mathrm{~m}^{2}$ and a tank size of $150 \mathrm{~L}$ can provide up to $70 \%$ of the domestic hot water demand of a typical household in the UK. Based on the data from the solarthermal heating model at household scale, performance maps are developed to estimate the heat output from different systems under varying operating conditions. These are then used to assess solar-thermal systems in a heating-sector decarbonisation model. The model is a mixed-integer linear programming model that optimises the capacity expansion of the UK domestic heating sector until 2050 as well as the annual operating schedules of the different technologies. It is found that solar-thermal heating requires incentives in order to be competitive with hydrogen boilers or electric heat pumps. However, if solar thermal collectors are deployed, they provide significant system value by reducing the demand for carbon-neutral hydrogen or electricity. An investment incentive of $£ 3,000$ per solar-thermal system leads to a deployment of over $150 \mathrm{GW}$ of solar-thermal capacity by 2050, which reduces the annual hydrogen demand by 240 TWh compared to the baseline without solar-thermal heating, while the electricity demand increases by 90 TWh due to heat pumps and electric resistive heaters being used as backup heating technologies.
\end{abstract}

\section{Keywords:}

Solar thermal; Heating decarbonisation; Energy system; Renewable energy; Optimisation.

\section{Introduction}

While the electricity sector has seen rapidly increasing penetration of renewable energy, the majority of domestic space heating and hot water provision systems in the UK still rely on natural gas. About $85 \%$ of residential buildings are connected to the gas grid and use boilers as the main heating technology, while offgrid buildings mainly use oil, liquid petroleum gas boilers or electric heating [1]. Natural gas is an unsustainable heating fuel, as it is a finite resource associated with harmful emissions [2]. About $18 \%$ of all UK carbon emissions in 2019 were attributed to the residential combustion of fuel [3], which comprises heating, cooking and garden machinery [4].

Alternatives to natural gas-based heating include: (i) electrification of heating using vapour-compression heat pumps; and (ii) boiler fuel-switching, i.e., substituting natural gas as fuel with hydrogen. Both options are considered in many published heating decarbonisation scenarios. In its Sixth Carbon Budget report [5], the Committee on Climate Change (CCC) presents a balanced net-zero pathway that requires $52 \%$ of the UK's heat demand in 2050 to be met by heat pumps, $42 \%$ by low-carbon district heat and $5 \%$ by hydrogen boilers. Additionally, a scenario with high penetration of hydrogen heating is presented. Similarly, the scenarios presented in the latest Future Energy Scenarios report [6] by National Grid expect all heat in 2050 to be supplied from electricity or hydrogen. Using electricity and hydrogen as energy vectors to provide space heating and hot water will only be as sustainable as the electricity and hydrogen production, and high deployment of the associated heating technologies will result in considerable additional electricity and hydrogen demands. National Grid's high-electrification scenario will result in about $82 \mathrm{TWh}$ of electricity demand and $18 \mathrm{TWh}$ of hydrogen demand for residential heating alone, while the hydrogen-centred scenario requires about $45 \mathrm{TWh}$ of electricity and $225 \mathrm{TWh}$ of hydrogen [6]. These high demands put a lot of pressure 
on low- or zero-emission electricity and hydrogen generation. Quiggin and Buswell [7] show that the levels of heating electrification assumed in different decarbonisation scenarios result in an increase of the peak electricity demand in the range of 10 to $55 \mathrm{GW}$. Eyre and Baruah [8] highlight that high levels of heat electrification will result in increased demand peaks in winter, where the heat demand is high and heat pump efficiencies low. Heat pumps are expected to add over $40 \mathrm{GW}$ to the current peak of $\sim 60 \mathrm{GW}$, which is seen as a challenge for electricity generation and distribution systems. Hybrid heat pumps with peaking gas boilers are proposed as a potential remedy. Similarly, Zhang et al. [9] identified hybrid heat pumps as the most economical solution, stating that about $100 \mathrm{GW}$ of additional electricity generation capacity would be required if only heat pumps without backup boiler would be deployed. These scenarios are however based on the old $80 \%$ emission reduction target. In order to reach net-zero, emissions from peaking gas boilers would have to be offset by negative emission technologies. Sunny et al. [10] investigated the potential of carbon-neutral hydrogen-based heating. They show that a full decarbonisation requires about $50 \mathrm{GW}$ of hydrogen production capacity. The peak demand is estimated to be $205 \mathrm{GW}$, meaning that the proposed system relies heavily on large-scale hydrogen storage with capacities in the order of 50 to $100 \mathrm{TWh}$.

Solar-assisted heating systems are a potential candidate to reduce the high electricity and/or hydrogen demands. Solar-thermal collectors are inherently low-emission systems able to provide heat from a renewable source. Though solar-assisted heating is popular in many southern European countries and has been successfully deployed in countries with less-favourable climate, such as Denmark [11,12], it is often neglected as a sustainable heating option in UK heat decarbonisation pathways. Renaldi and Friedrich [13] analysed potential solar district heating systems in two UK locations, showing that with seasonal energy storage, solar fractions of almost $80 \%$ can be reached in the south-west of England, though at higher costs than incumbent heating systems. Ma et al. [14] analysed the feasibility of purely solar-thermal heating in the UK. It is found that average homes would require 26 to $77 \mathrm{~m}^{2}$ of collector area and a storage capacity of 6 to $8 \mathrm{GWh}$ (which translates to 32 to $44 \mathrm{~m}^{3}$ of high energy-density sorption storage) to meet their heating demand solely with solar collectors. Such systems sizes are impractical; however, significantly smaller system may still make a sizeable contribution to the annual heat generation. Herrando et al. [15] investigated the performance of combined PV and solar-thermal systems in the UK. Results show that a $15-\mathrm{m}^{2}$ system can supply up to $51 \%$ of the annual electricity demand and $36 \%$ of the annual hot water demand of a typical house, when paired with a 150-L water storage tank. An economic analysis [16] yielded payback times of $9-11$ years for such a system, if supported by electricity feed-in tariffs and the Renewable Heat Incentive. Greening and Azapagic [17] present a life-cycle environmental-impact analysis of solar-thermal systems in the UK, concluding that impacts on global warming and depletion of fossil resources are $88 \%$ and $83 \%$ lower compared to gas boilers. However, impacts on other factors such as human and eco-toxicity are significantly higher, and the need to reduce resource use in the production of collectors is highlighted.

This study aims to investigate the potential of solar-assisted heating in the UK. Based on manufacturer data on collector costs and performance, representative systems are modelled, and performance maps are derived. A capacity-expansion and dispatch optimisation model of the UK heating system is then used to investigate the value of different solar-thermal systems in heat decarbonisation scenarios. The novelty of this work is the investigation of different solar-assisted heating systems in a UK context based on a review of commerciallyavailable collectors and the assessment of the competitiveness of different types of solar-thermal collectors in a whole-system model of the UK domestic heating sector.

\section{Models and data}

The potential of solar-thermal systems in the UK is assessed using a model of residential solar heating systems and a whole-system model of the UK heating sector. Four representative solar-thermal collectors are considered: high-performance (HP) and low-cost (LC) models of both flat-plate collectors (FPCs) and evacuated-tube collectors (ETCs) are selected from a range of commercially-available modules.

\subsection{Solar-thermal system model}

A solar-thermal system model is developed to simulate the performance of different solar-thermal collectors over a year with a time-resolution of $1 \mathrm{~h}$. The collector efficiency is modelled using the classic quadratic efficiency equation based on the ratio of the collector-to-ambient temperature difference, $T_{\mathrm{col}}-T_{\mathrm{amb}}$, to the incident solar irradiation, $I_{\text {solar }}$ :

$$
\eta=\eta_{0}+c_{1} \frac{T_{\mathrm{col}}-T_{\mathrm{amb}}}{I_{\mathrm{solar}}}+c_{2} \frac{\left(T_{\mathrm{col}}-T_{\mathrm{amb}}\right)^{2}}{I_{\mathrm{solar}}}
$$

The optical efficiency, $\eta_{0}$, as well as the heat loss coefficients, $c_{1}$ and $c_{2}$, are taken from collector datasheets. The collector temperature is calculated as the average between inlet and outlet temperatures. The model assumes collectors to be installed at a tilt angle of $34^{\circ}$ facing due south, which is the optimal orientation for the UK [18]. The population centre of Britain, located in Leicestershire [19], is selected as the representative site. Temperature and irradiation data are taken from a typical meteorological year generated for this location by the PVGIS tool [20]. The incident irradiation comprises: (i) a direct fraction, calculated from the direct normal 
irradiance; (ii) a diffuse fraction, calculated from the diffuse horizontal irradiance; and (iii) a reflected fraction, calculated assuming a surface albedo of 0.3 .

The model also includes an idealised stratified water storage tank, the volume of which can be varied. The tank is assumed to have $80 \mathrm{~mm}$ of glass wool insulation with a thermal conductivity of $0.04 \mathrm{~W} /\left(\mathrm{m}^{*} \mathrm{~K}\right)$. Hourly heat losses are calculated based on the temperatures of each volume of the stratified tank. The heat transfer fluid in the collector is a water-glycol mixture, as is typically used in solar-thermal systems. The heat transfer to the storage tank is assumed to be loss-free. The system can be operated either: (i) with a fixed mass flowrate through the collector, resulting in variable outlet temperatures; or (ii) with a variable flowrate controlled (within bounds provided by the manufacturer) to target a constant collector outlet temperature set to $55^{\circ} \mathrm{C}$, which is the minimum temperature required for domestic hot water (DHW). The system can be modelled for either DHW or space heating applications. The DHW demand for an average house is taken from Herrando et al. [15], while the space heating demand is estimated by applying the relative profile of Sansom [21] to the average dwelling from the Cambridge Housing Model [22]. In the DHW case, the tank is replenished with mains water, the monthly average temperature of which is taken from Davies et al. [23]. For space heating, a water return temperature of $35^{\circ} \mathrm{C}$ is assumed, which is typical for a low-temperature heating system.

\subsection{Solar-thermal collector data}

In order to estimate the cost and performance ranges of solar-thermal collectors and to select representative modules, datasheets and prices of commercially available flat-plate and evacuated-tube collectors are investigated. The assembled data [24] includes performance data for 28 FPCs and 25 ETCs, with prices available for 19 FPCs and 12 ETCs. Only prices from 2016 onwards are used, as old values are no longer representative. The efficiency curves of the different collectors for an ambient temperature of $25^{\circ} \mathrm{C}$ and an irradiance of $1000 \mathrm{~W} / \mathrm{m}^{2}$ are shown in Fig. 1. The efficiency is hereby defined as ratio of heat output to the gross collector area multiplied by the irradiance. It should be noted that ETCs typically have incidence angle modifiers larger than 1 for a wide range of incidence angles. The incidence angle modifier is the ratio of optical efficiency at a certain incidence angle to the optical efficiency at normal incidence, hence the heat output is higher than the optical efficiencies suggest. The collector prices exhibit large variation. FPC prices range from $109 £ / \mathrm{m}^{2}$ to $307 £ / \mathrm{m}^{2}$ with a median of $196 \mathrm{\Sigma} / \mathrm{m}^{2}$; ETC prices are in the range of $116 £ / \mathrm{m}^{2}$ to $526 \mathrm{\Sigma} / \mathrm{m}^{2}$ with a median of $294 \mathrm{\Sigma} / \mathrm{m}^{2}$. From the data, four representative collectors are selected. The necessary criterium was the availability of cost data from 2020, further it was attempted to cover the range of different systems that are available. The parameters of the four collectors selected for this study are summarised in Table 1.

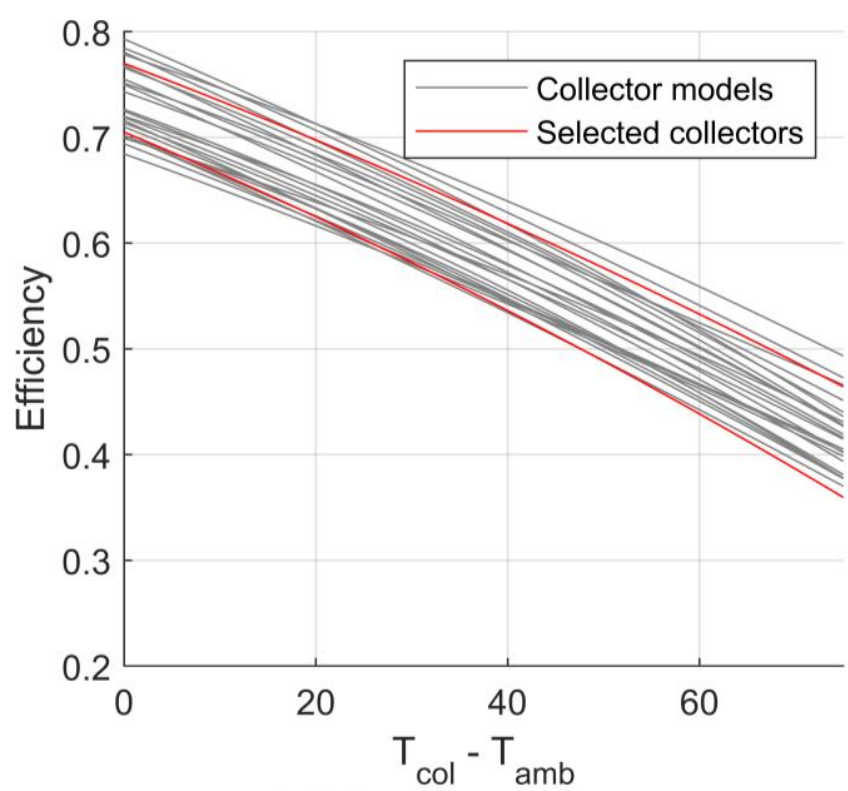

(a) Flat-plate collectors

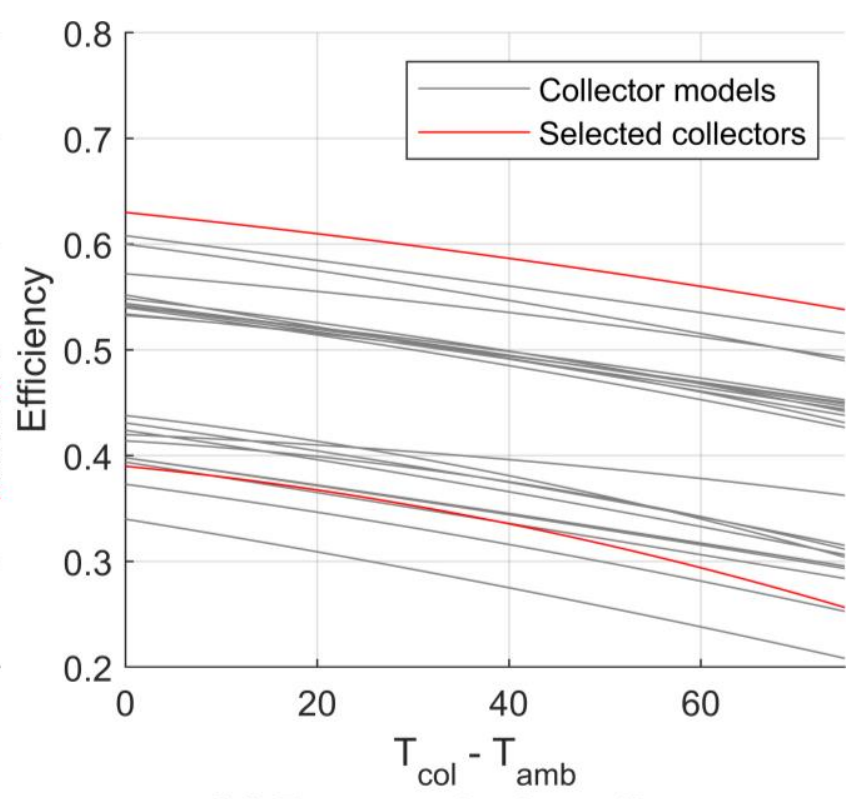

(b) Evacuated-tube collectors

Fig. 1. Efficiency curves of different (a) flat-plate collectors and (b) evacuated-tube collectors currently available on the market for different collector versus ambient temperature differences $T_{\mathrm{col}}-T_{\mathrm{amb}}$ [24]. The efficiency curves of the selected representative collectors are highlighted in red. 
Table 1. Efficiency data and price of the representative commercially-available solar-thermal collectors selected for this case study. The four models were picked from a library of solar-thermal collectors available on the market [24].

\begin{tabular}{lllll}
\hline Collector & $\eta_{0}$ & $c_{1}$ in $\mathrm{W} /\left(\mathrm{Km}^{2}\right)$ & $c_{2}$ in $\mathrm{W} /\left(\mathrm{K}^{2} \mathrm{~m}^{2}\right)$ & Price in $£ / \mathrm{m}^{2}$ \\
\hline High-performance FPC & 0.770 & 3.45 & 0.0083 & 228 \\
Low-cost FPC & 0.705 & 3.78 & 0.0110 & 180 \\
High-performance ETC & 0.63 & 0.93 & 0.0040 & 340 \\
Low-cost ETC & 0.39 & 0.88 & 0.0120 & 116 \\
\hline
\end{tabular}

\subsection{UK heating sector model}

Solar-thermal systems are evaluated in a whole-energy system context using a model of the UK heating sector. The model was developed using the same principles as the Electricity Systems Optimisation (ESO) model presented by Heuberger et al. [25,26]. The heating sector model is a capacity expansion and dispatch optimisation model that simultaneously optimises technology portfolios and their operation schedules, minimising the total system costs comprising capital expenditure and operating expenditure including fuel costs. Future costs are hereby discounted by $3.5 \% / y e a r$. Starting from the incumbent technology mix in 2020, the model optimises investment and decommissioning decisions every 5 years up until 2050. For each of these decision years, the dispatch is optimised. The model hereby assumes rational cost-driven decision-making and perfect foresight. A mixed-integer linear programming (MILP) model formulation is used to allow discrete investment and decommissioning decisions. Minimum technology sizes are enforced, and units can only be decommissioned as a whole. To reduce computational complexity, the model does not consider full-hourly time series but rather representative time slices. By default, the year is represented by 13 typical days with hourly a resolution. Twelve of the days are selected by a kmedoids clustering algorithm, considering both, the heat demand, and the solar irradiance profiles. The $13^{\text {th }}$ day is the peak day with the highest heat demand to ensure that heating systems are sized appropriately even if a typical-day formulation is used. The optimisation model is implemented in GAMS and solved by the CPLEX MILP solver. Python is used for data pre- and postprocessing and plotting of the optimisation results.

Heating systems are typically decentralised. Therefore, the model optimises the heating technology portfolios and operation schedules for individual representative households. The household data, including annual heating demands, are taken from the Cambridge Housing Model [22], which is based on data from the 2011 English Housing Survey and performs Standard Assessment Procedure (SAP)-based energy calculation for about 15,000 stereotypical dwellings. A kmeans clustering algorithm is used to select representative households for the heating sector model, all dwellings from the housing model are assigned to the nearest cluster centroid. The housing model only includes about 21.4 million households, all in England, while the entire UK has 27.8 million households [27]. Therefore, the number of households in each cluster is scaled by a factor of 27.8/21.4 so that the total heat demand is representative of the UK. The implicit assumption is that households in other parts of the UK are similarly distributed and have comparable heating demands as English households. The housing model only provides annual heating demand figures. Hourly demand curves for each representative household are determined using the profiles of Watson et al. [28] and ambient temperature data from the aforementioned typical meteorological year dataset. In line with the balanced scenario developed by the CCC [5], heating demand is expected to decrease by $12 \%$ by 2050 . The model assumes a linear decrease over the years for each of the representative households.

A number of different domestic-scale heating technologies are considered in the model. In addition to the previously introduced four different solar collectors, natural-gas, and hydrogen boilers as well as power-driven air-source heat pumps (ASHPs) and resistive electric heaters are modelled. Key technology parameters are summarised in Table 2. The fixed investment costs include installation costs that are independent of the heating capacity. Values for gas boilers and ASHPs are taken from a report by the Department for Business, Energy \& Industrial Strategy (BEIS) [29]. Estimates for total solar-thermal system installation costs including collectors vary from $£ 3,000$ for $3 \mathrm{~m}^{2}$ and $£ 4,500$ for $6 \mathrm{~m}^{2}$ [30] to $£ 4,000$ to $£ 5,000$ for $3.6 \mathrm{~m}^{2}$ [31]. Based on these values and the average collector costs, fixed investment costs are estimated to be in the range of $£ 3,000$. All variable investment cost values are based on market research data. The gas boiler costs are based on data from over 50 domestic gas boilers available on the British market, and the ASHP costs were calculated as average of nearly 100 commercially available units. Maintenance costs of boilers [32], ASHPs [33] and solar-thermal systems [34] are based on prices quoted by manufacturers and trades companies. A constant efficiency of $90 \%$ is assumed for boilers, while a temperature-dependant function derived from manufacturer data is used to determine the ASHP efficiency [35]. Hydrogen boilers are expected to reach similar costs and efficiencies as natural gas boilers if the cumulative production volume per manufacturer reaches 100,000 [36,37]. 
Table 2. Key model parameters of domestic heating technologies. NG stands for natural gas, H2 stands for hydrogen. The solar-thermal collectors are abbreviated as combination of high-performance (HP) or low-cost (LC) and flat-plate collector (FPC) or evacuated-tube collector (ETC). REH stands for resistive electric heater.

\begin{tabular}{llllllll}
\hline & $\begin{array}{l}\text { Min. } \\
\text { size }\end{array}$ & $\begin{array}{l}\text { Max. } \\
\text { size }\end{array}$ & $\begin{array}{l}\text { Fixed } \\
\text { investment } \\
\text { costs in } £\end{array}$ & $\begin{array}{l}\text { Variable } \\
\text { investment } \\
\text { costs in } / / \mathrm{kW}\end{array}$ & $\begin{array}{l}\text { Maintenance } \\
\text { costs in } \\
\text { £/year }\end{array}$ & Efficiency & $\begin{array}{l}\text { Lifetime } \\
\text { in years }\end{array}$ \\
\hline NG boiler & $15 \mathrm{~kW}$ & $50 \mathrm{~kW}$ & 1720 & 28 & 100 & 0.9 & 20 \\
H2 boiler & $15 \mathrm{~kW}$ & $50 \mathrm{~kW}$ & 1720 & 28 & 100 & 0.9 & 20 \\
ASHP & $4 \mathrm{~kW}$ & $12 \mathrm{~kW}$ & 3720 & 570 & 240 & variable & 20 \\
REH & $4 \mathrm{~kW}$ & $15 \mathrm{~kW}$ & - & 95 & - & 1 & 20 \\
HP-FPC & $2 \mathrm{~m}^{2}$ & $15 \mathrm{~m}^{2}$ & 3000 & 300 & 75 & Table 1 & 20 \\
LC-FPC & $2 \mathrm{~m}^{2}$ & $15 \mathrm{~m}^{2}$ & 3000 & 260 & 75 & Table 1 & 20 \\
HP-ETC & $2 \mathrm{~m}^{2}$ & $15 \mathrm{~m}^{2}$ & 3000 & 540 & 75 & Table 1 & 20 \\
LC-ETC & $2 \mathrm{~m}^{2}$ & $15 \mathrm{~m}^{2}$ & 3000 & 300 & 75 & Table 1 & 20 \\
\hline
\end{tabular}

Hot water storage tanks are modelled as a domestic energy storage option. The model assumes investment costs of $106 £ / \mathrm{kWh}$ and heat losses of $16 \% /$ day based on data from commercially available systems. Due to the typical-day formulation of the model, the storage has to be balanced for each typical day, thus preventing seasonal energy storage. Heat can however be stored from one afternoon of a typical day to the next morning. Electricity, natural gas and hydrogen are modelled as fuels, while solar energy is available as a resource free of charge. The electricity price is estimated to be $18.6 \mathrm{p} / \mathrm{kWh}$ [38]. The carbon intensity in 2020 is assumed to be $0.26 \mathrm{kgCO}_{2}$-eq/kWh [39] and modelled to decrease in line with the CCC's central scenario [5], reaching virtually zero in 2035. Natural gas is available at $3.9 \mathrm{p} / \mathrm{kWh} \mathrm{[40]} \mathrm{and} 0.20 \mathrm{kgCO}_{2}$-eq/kWh [39]. Hydrogen is assumed to be a carbon-neutral fuel based on data from Sunny et al. [10], who estimated average costs to be $6.8 \mathrm{p} / \mathrm{kWh}$. The authors further estimate that distribution-related charges of up to $25 \%$ will be added, resulting in a hydrogen price of $8.5 \mathrm{p} / \mathrm{kWh}$ for domestic customers.

The model can consider individual carbon emission targets for each of the decision years, and a cumulative carbon emission budget. Build-rate constraints can be used to limit the deployment rates of new technologies to ensure that manufacturing and installation capacities are not exceeded. The UK government's "Plan for a Green Industrial Revolution" [41] aims for $1 \mathrm{GW}$ of hydrogen production capacity to be available in 2025 and 5 GW in 2030; therefore, it is assumed that the capacity can be increased fivefold every 5 years. About 28,000 heat pumps were installed in the UK in 2019 [42]. Assuming an average capacity of $8 \mathrm{~kW}$, the initial build rate is $224 \mathrm{MW} / \mathrm{year}$. It is again assumed that this build rate can be increased by a factor 5 every 5 years, since data from Germany show that an increase by a factor of 1.4 within one year is possible [43]. The cumulative capacity of solar thermal collectors in the UK was 1 GW in 2017 and 2018 [44], but no significant capacity was added in the last years [45]. The model assumes an initial build rate of $100 \mathrm{MW} / \mathrm{year}$ and multiplier of 5 per 5 years.

It should be noted that the model does not consider future price reductions e.g., in form of learning curves. While the price of mature technologies such as gas boilers is not expected to change drastically, other technologies such as heat pumps and solar-thermal collectors may see significant price reductions if production capacities are scaled up. The hydrogen prices assumed in the model are based on calculations assuming all heating in the UK to be provided from hydrogen. If the hydrogen penetration is smaller, prices may be higher.

\section{Solar-thermal system performance}

The performance of the four representative solar-thermal collectors is modelled over a typical year in the UK. For the DHW baseline case, the modelled systems each consist of $4 \mathrm{~m}^{2}$ of one of the solar collectors and a $160 \mathrm{~L}$ hot water storage tank. The daily hot water demand is about $120 \mathrm{~L}$, which is a typical value for a 4-person household [15]. The location receives a cumulative global horizontal irradiation of $1030 \mathrm{kWh} / \mathrm{m}^{2}$ over the typical year. The global irradiation on the collector at a $34^{\circ}$ angle is $1150 \mathrm{kWh} / \mathrm{m}^{2}$. The performance of the different systems is summarised in Table 3 . All collectors are able to supply a significant share of the annual hot water demand. The solar fraction, defined as percentage of demand supplied by solar energy, ranges from $59 \%$ to $70 \%$, with the high-performance collectors unsurprisingly reaching the highest values. The gross heat output is the highest for the HP-ETC, followed by the HP-FPC, the LC-FPC and the LC-ETC. The variance between HP and LC options shows that neither ETCs nor FPCs have an inherent performance advantage over to other. The specific heat generation of the LC-ETC is the smallest due too large spacing between the tubes, which inflates the gross area in comparison to the absorber area. Despite the significantly higher gross heat output of the HP-ETC compared to the HP-FPC, both systems achieve nearly identical solar fractions, suggesting that a larger portion of the heat generated by the HP-ETC cannot be used due to mismatch of generation and demand. 
The specific costs displayed in Table 3 were calculated as ratio of annualised investment costs (including storage and installation) to heat output, using the cost values shown in Table 2. The systems only show little differences in terms of costs per useful output, and the variations are certainly within the uncertainty bounds of collector costs and performance. Therefore, for the baseline case no system can be identified as superior to the others, though collectors with a high specific heat output may be beneficial in practical settings.

The HP-ETC shows a high specific heat generation and competitive costs. It is selected for further investigation of different system layouts. The aim is to identify optimal collector/tank size combinations and to investigate the potential of solar-assisted space heating and long-term energy storage. Collector sizes up to $50 \mathrm{~m}^{2}$ and tank sizes up to $5000 \mathrm{~L}$ are considered, though such large systems are likely impractical for most domestic households due to limited space on the roof for the collectors and in the house for the storage tank.

Table 3. Performance of different solar-thermal collectors for hot water heating. A typical residential system with $4 \mathrm{~m}^{2}$ of gross collector area and a 160-L storage tank is modelled as a baseline case.

\begin{tabular}{cccccc}
\hline & $\begin{array}{c}\text { Annual heat } \\
\text { output in } \mathrm{kWh}\end{array}$ & $\begin{array}{c}\text { Annual specific } \\
\text { heat in } \mathrm{kWh} / \mathrm{m}^{2}\end{array}$ & $\begin{array}{c}\text { Solar } \\
\text { fraction }\end{array}$ & $\begin{array}{c}\text { System costs per } \\
\text { heat output in } \mathrm{p} / \mathrm{kWh}\end{array}$ & $\begin{array}{c}\text { System costs per useful } \\
\text { heat output in } \mathrm{p} / \mathrm{kWh}\end{array}$ \\
\hline HP-FPC & 2080 & 520 & 0.69 & 0.20 & 0.30 \\
LC-FPC & 1770 & 440 & 0.63 & 0.23 & 0.31 \\
HP-ETC & 2320 & 580 & 0.70 & 0.19 & 0.31 \\
LC-ETC & 1570 & 390 & 0.59 & 0.24 & 0.32 \\
\hline
\end{tabular}

The solar fraction depends on the collector area and the storage tank size. Fig. 2 shows the solar fractions achieved by systems of different size. In the DHW case, almost all of the annual demand can be provided from solar energy if the collector is sufficiently large, and even small systems can still provide a significant share of heat required for DHW. The results also show that large solar fractions can be achieved with moderate storage tank sizes of 100 to $200 \mathrm{~L}$. In fact, the marginal value of larger tank sizes decreases rapidly above $100 \mathrm{~L}$, and very large tanks can even decrease the solar fraction due to higher heat losses. Solar-assisted space heating systems struggle to reach solar fractions larger than $55 \%$ even with very large collector areas of $50 \mathrm{~m}^{2}$ and tank sizes larger than $1000 \mathrm{~L}$. Moreover, an increase in tank value over a certain value again has a negative impact, suggesting that heat losses from the tank are too high to facilitate seasonal energy storage at household scale. Increasing the storage insulation thickness from $80 \mathrm{~mm}$ to $200 \mathrm{~mm}$ improves the maximum achievable solar fraction with the considered sizes by 1.5 percentage points.

Fig. 3 shows the solar system costs per heat output. The DHW system exhibits a cost minimum at collector sizes of 4 to $8 \mathrm{~m}^{2}$ and tank sizes of 100 to $200 \mathrm{~L}$, which is in the range of typical domestic installations. The solar-assisted space heating system achieves even lower relative costs for a large range of collector sizes and storage tank sizes of 500 to $1000 \mathrm{~L}$. It should be noted that the costs of the backup heating technology and the fuel it requires are not included in these calculations.

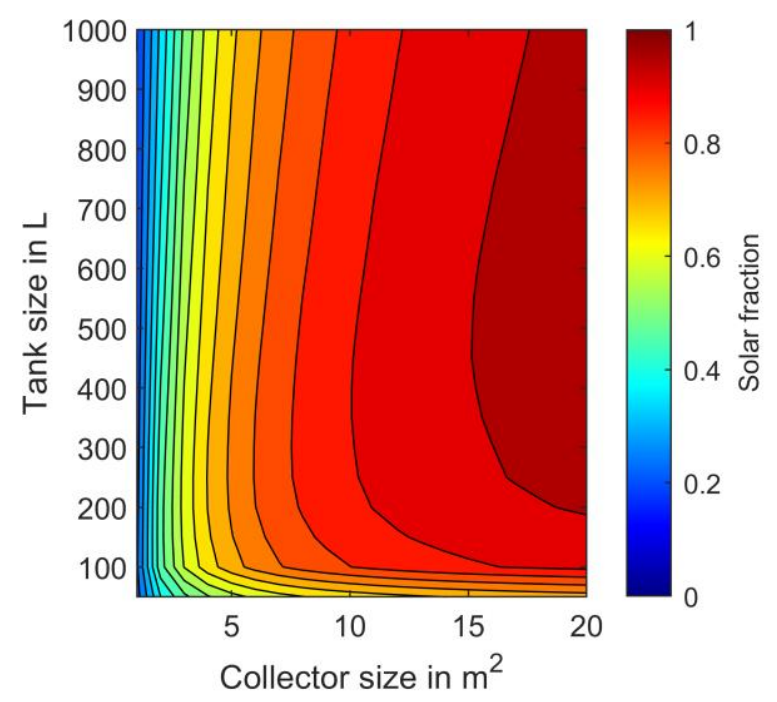

(a) Domestic hot water

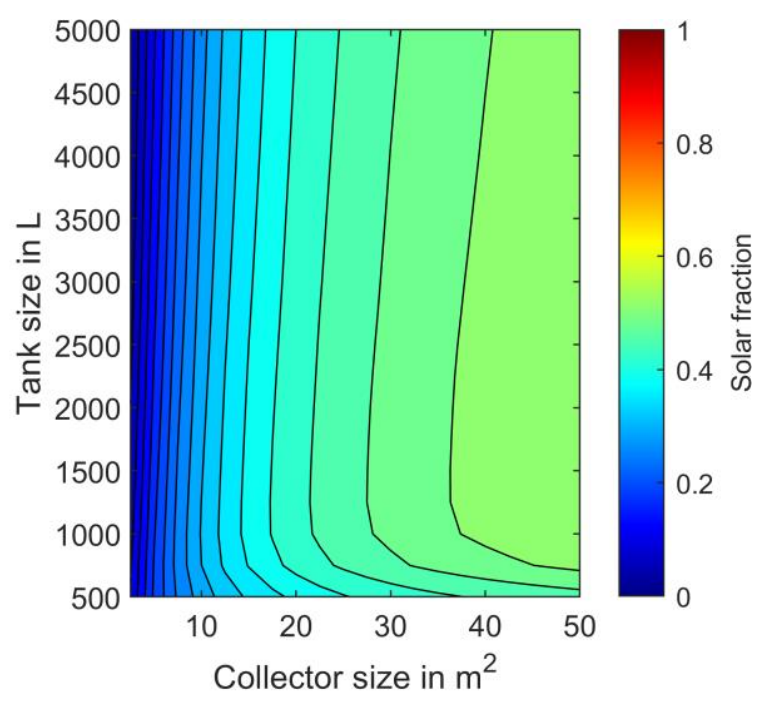

(b) Space heating

Fig. 2. Solar fractions over a typical year in the UK for different collector areas and storage tank sizes of systems for: (a) domestic hot water; and (b) space heating. It is assumed that the collectors are installed at a $34^{\circ}$ angle facing due south, the global annual irradiance is $1150 \mathrm{kWh} / \mathrm{m}^{2}$. 


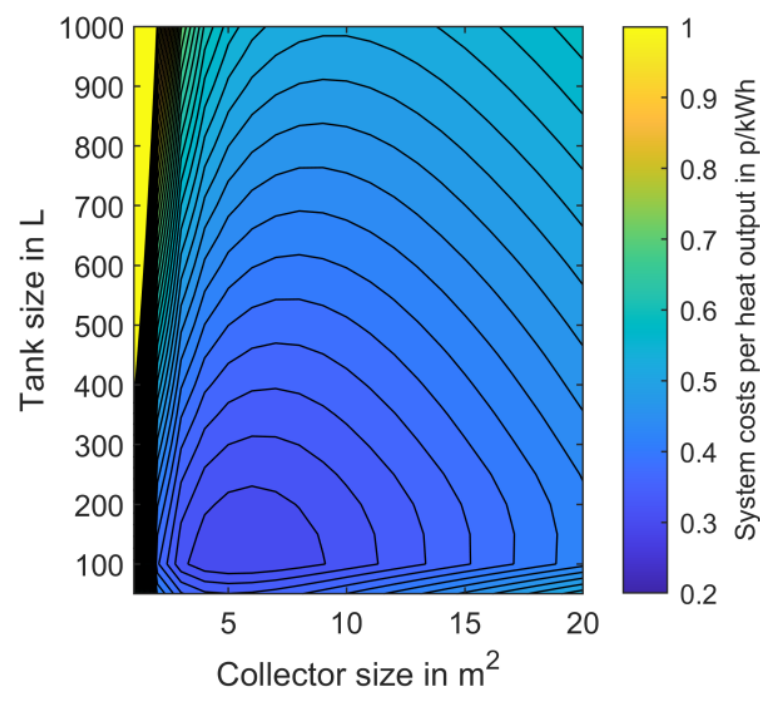

(a) Domestic hot water

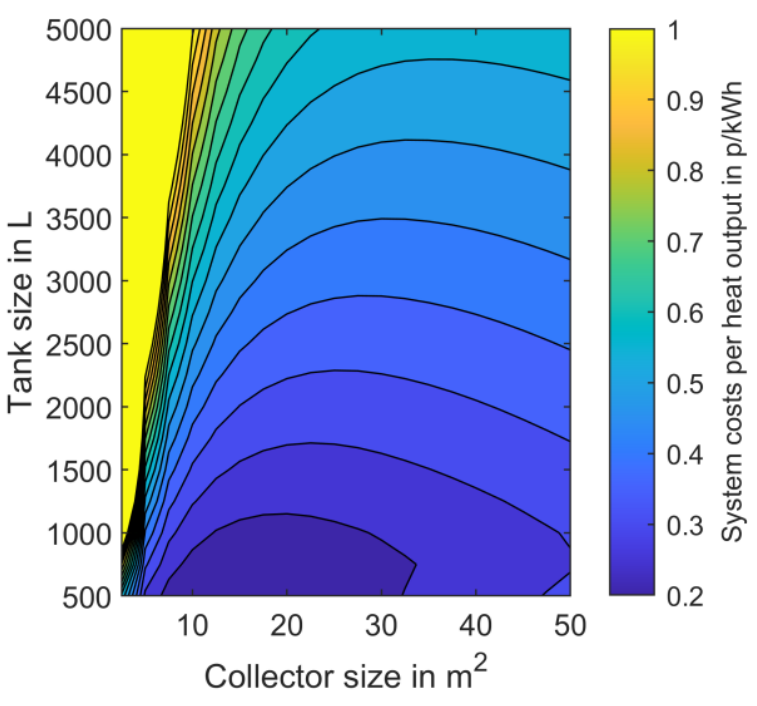

(b) Space heating

Fig. 3. System cost per heat output over a typical year in the UK for different collector areas and storage tank sizes of systems for: (a) domestic hot water; and (b) space heating. It is assumed that collectors are installed at a $34^{\circ}$ angle facing due south, the global annual irradiance is $1150 \mathrm{kWh} / \mathrm{m}^{2}$. Costs are calculated as sum of annualised investment costs of collector and tank, including installation, assuming an interest rate of $3.5 \%$.

\subsection{Performance characteristics for use in whole-system models}

The full solar-thermal system model including collectors and tank is too complex to be implemented in wholeenergy system models. Therefore, simple performance maps are derived to predict the heat output from different systems. An analysis of the results from the solar-thermal system model shows that the capacity factors, defined as ratio of heat output under specific conditions to heat output under standard conditions, correlate linearly with the incident irradiance on the collector. The relationships between capacity factors and irradiance are displayed in Fig. 4. Above an irradiation threshold, the capacity factors increase linearly with the irradiance. Tests with different collector and storage sizes show that these relationships are valid for a wide range of systems. Using this data, the capacity factors can be calculated from irradiation data in a preprocessing step. The whole-system model can then optimise the nominal capacities of solar-thermal systems and easily calculate the heat output at each time step from the capacity factors.
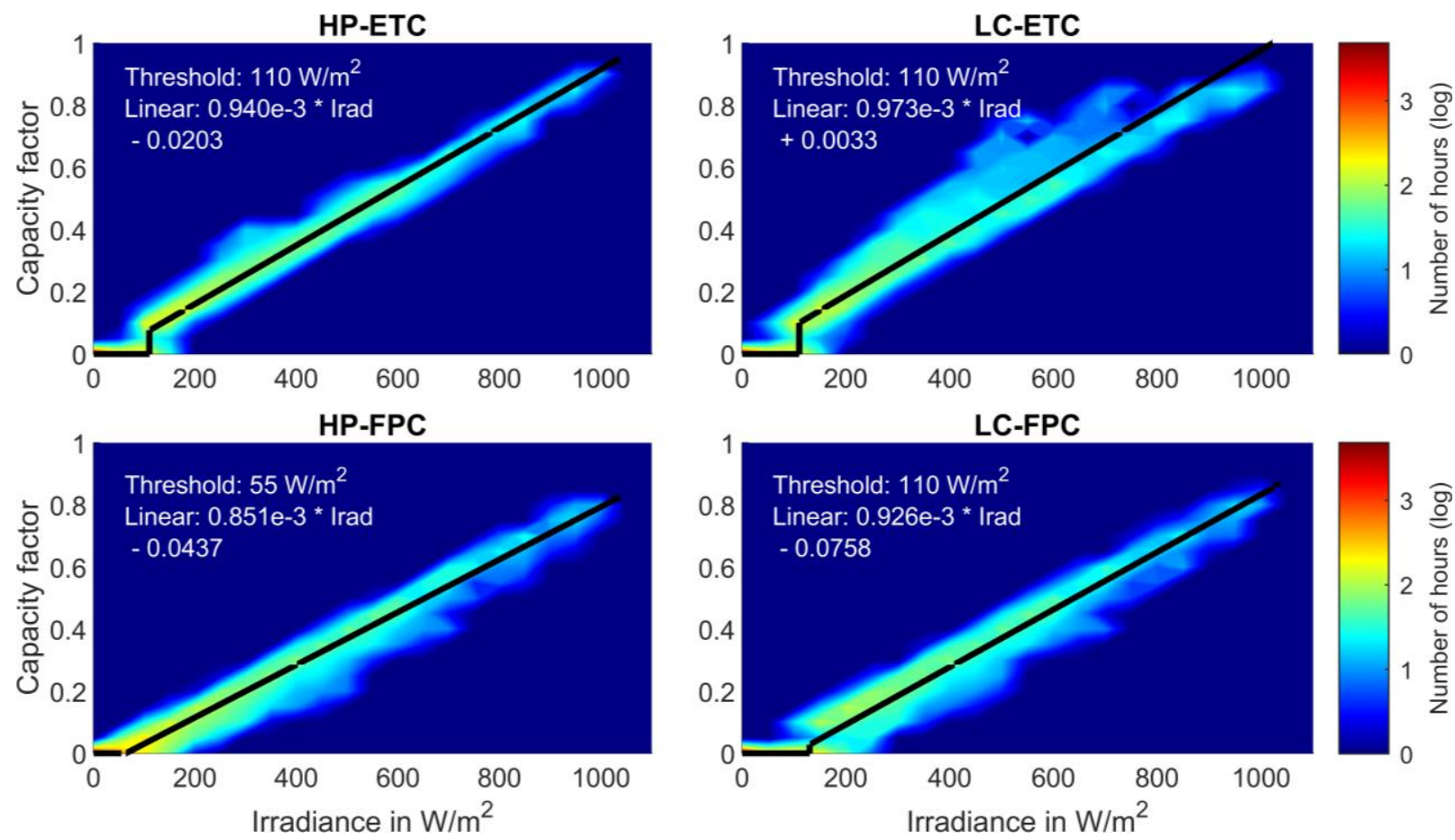

Fig. 4. Correlation of capacity factors with irradiance Irad. The colours correspond to the frequency with which the operating conditions occur over a typical year in the UK. The black line represents the fitted linear function, the corresponding equations are displayed in the plots. 


\section{Solar-thermal heating in a whole-system context}

The potential value of solar-thermal collectors for the decarbonisation of heating is assessed using the UK heating sector model, described in Section 2.3. The heating technology portfolio and dispatch is optimised for five representative households, from which then values for the total UK housing stock are extrapolated.

Without any emission constraints, gas boilers continue to get deployed until 2050, suggesting that, at current prices, they are the cheapest domestic heating technology. If a net-zero carbon emission in 2050 constraint is enforced, all representative households switch from gas boilers to hydrogen boilers as only heating technology. This transition happens instantaneously in 2050 if no build-rate constraints are in effect, or over time starting in 2035 to allow for a ramp-up of hydrogen production capacity. If linear emission reduction targets are set rather than only enforcing net-zero in 2050 , which decreases the cumulative harmful emissions, the model first deploys heat pumps and direct electric heating until later when more decarbonisation is required the whole systems transfers to hydrogen boilers.

The costs of carbon-neutral hydrogen are uncertain. In their cost sensitivity analysis, Sunny et al. [10] estimate that costs of hydrogen for heating may be up to $8.5 \mathrm{p} / \mathrm{kWh}$. With distribution-related charges of $25 \%$ added, this yields a maximum price of $10.6 \mathrm{p} / \mathrm{kWh}$. If these higher hydrogen costs are assumed, the model deploys electric heat pumps and resistive heating. The same is true if no carbon-neutral hydrogen is available at all.

\subsection{Incentives for solar-thermal systems}

Solar-thermal heating systems require incentives to be cost-competitive under default cost assumptions but provide significant system value if deployed. Installations in the UK are currently supported under the Domestic Renewable Heat Incentive scheme, a government incentive aimed to promote sustainable heating systems such as heat pumps, biomass boilers and solar water heating. For solar-thermal collectors, homeowners are paid $21.37 \mathrm{p} / \mathrm{kWh}$ of estimated annual heat generation for seven years [46]. If a permanent incentive of $21.37 \mathrm{p} / \mathrm{kWh}$ of generated solar heat is added to the model, large solar-thermal capacities get deployed. The optimisation results show that with the incentive it is optimal to install solar-thermal collectors for three of the five representative households used to model the UK building stock, while for the other two households heating systems comprising only a hydrogen boiler are cheaper. Low-cost ETCs and FPCs are hereby the preferred collector types, presumably because they have the lowest investment costs of the four considered collectors. Since solar energy is not always available, these households require backup heating systems. Resistive backup heating is optimal for one of the three households, while for the other two hydrogen boiler backups are preferrable. This suggests that electric heaters and boilers are both viable options to serve as backup system for solar-thermal heating. The electric resistive backup heating is preferred for the representative household with the smallest heat demand. In that case, the lower investment costs appear to outweigh the higher operating costs compared to hydrogen boilers. Compared to the baseline case without an incentive on solar-thermal heat, the total hydrogen demand in 2050 is reduced by 87 TWh or $28 \%$, though 29 TWh of electricity demand are added. Another effect of the deployment of solar-thermal collectors is a reduction of cumulative emissions from 2020 to 2050 by $12 \%$ due to solar-thermal as carbon-neutral technology being deployed earlier.

A similar effect can be reached by subsidising the investment in solar-thermal systems rather than paying an incentive per amount of generated heat. A payment of $£ 1,000$ upon installation of solar collectors leads to one of the five representative households in the optimisation model installing $5.9 \mathrm{~kW}\left(15 \mathrm{~m}^{2}\right)$ of low-cost ETCs by 2050. If the incentive is increased to 22,000 , the cost-optimal solution shows that three of the five households have a solar-thermal system with a hydrogen boiler as backup in 2050, while the last two use only hydrogen boilers. An even higher investment incentive of $£ 3,000$, which effectively covers the installation costs, results in all five representative households installing solar-thermal systems with capacities of $5.9 \mathrm{~kW}\left(15 \mathrm{~m}^{2}\right)$ in 2050 . Two of the households use electric resistive heaters as backup heating technology, another two use hydrogen boilers and the last one an electric heat pump. Together with the solar collectors, thermal storage tanks get deployed. Tank sizes range from 80 to $290 \mathrm{~L}$, showing that even though the MILP model can only consider daily thermal storage, hot water storage still provides value to the system if paired with solar-thermal collectors.

A comparison of the installed capacities over the years and the dispatch schedules between the baseline without incentives and the case with a $£ 3,000$ investment incentive is provided in Fig. 5 and Fig. 6. In total, over $150 \mathrm{GW}$ of solar-thermal capacity is installed in 2050. In this case, low-cost ETCs are preferred. Compared to the other collectors, low-cost ETCs have higher capacity factors meaning that the system is better utilised. The dispatch schedule shows that the solar generation is especially high when the heat demand is low (in summer). Therefore, the amount of fuel that can be saved it limited. Nonetheless, in 2050 the annual hydrogen demand is reduced by 240 TWh or $77 \%$ compared to the case without an investment incentive on solar-thermal collectors. A part of these savings however can be attributed to the switch to electric heating technologies. The annual electricity demand in 2050 is $90 \mathrm{TWh}$, while in the baseline case no electricity is used for heating. The savings in cumulative emissions until 2050 are $5 \%$, again due to the earlier deployment of carbon-neutral heating technologies. The cases with lower solar-thermal investment incentives also show substantial hydrogen savings of 65 TWh $(21 \%)$ and 12 TWh (4\%) respectively, compared to the baseline. In both cases, no electricity demand is added since only hydrogen boilers are used as backup heating technology. 
The limited thermal storage potential due to the typical-day model formulation likely underestimates the potential of solar-assisted heating, though results presented in Section 3 show that long-term energy storage at household scale is impractical. On the other hand, the study assumes that solar-thermal collectors can be installed for every household in the UK, when in reality installations may be difficult in some places due to limited space.

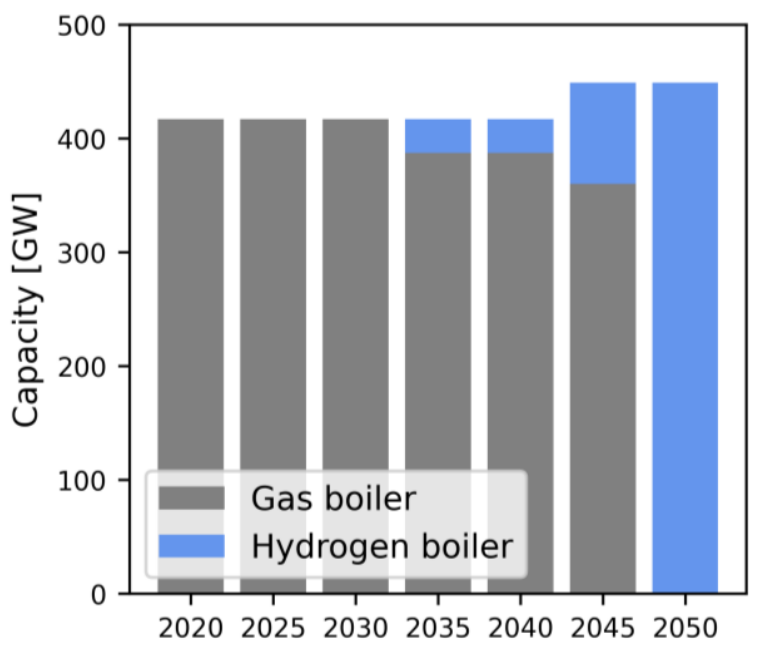

(a) no solar collector incentive

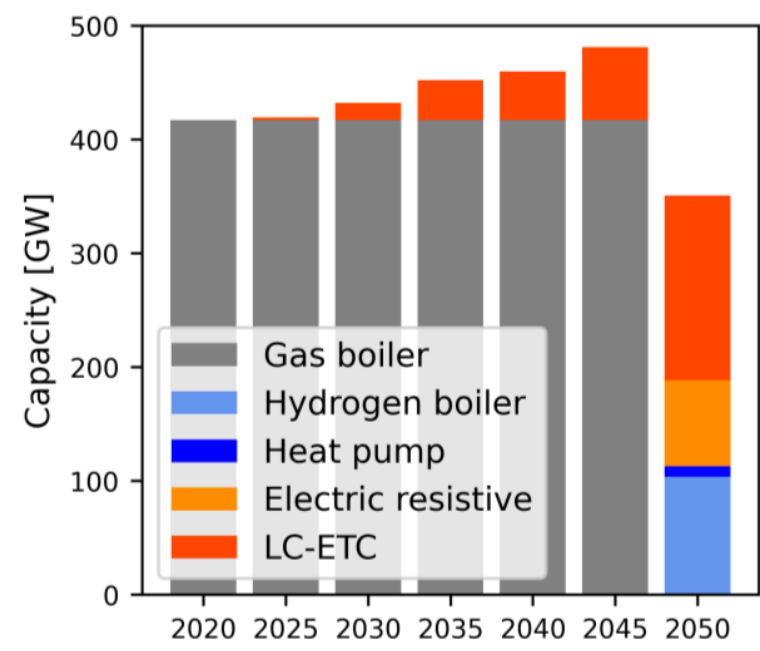

(b) $£ 3,000$ investment incentive

Fig. 5. Installed capacities: (a) if solar-thermal systems are not incentivised; and (b) if a £3,000 investment incentive is implemented.

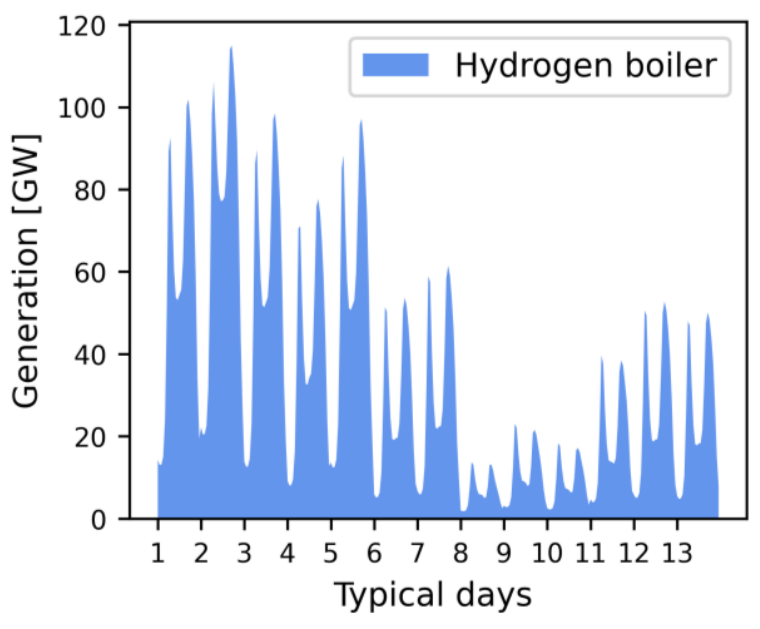

(a) no solar collector incentive

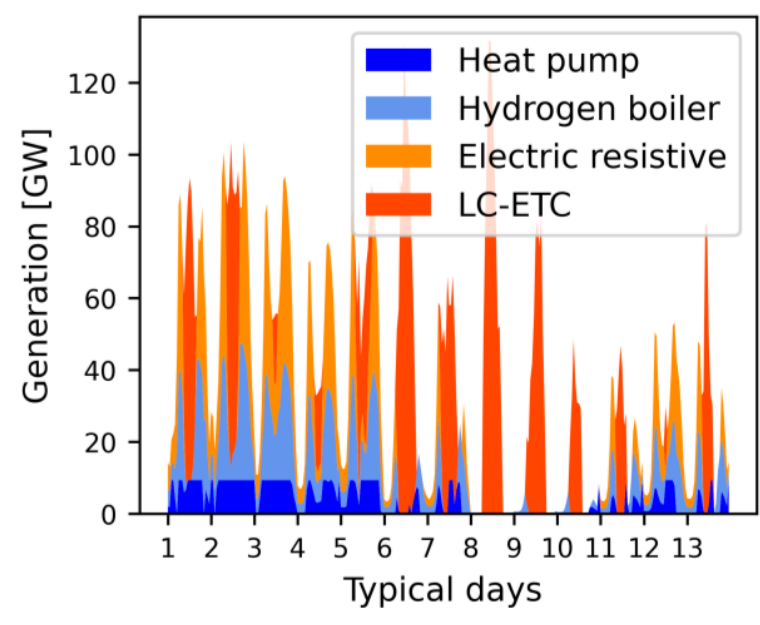

(b) $£ 3,000$ investment incentive

Fig. 6. Dispatch schedule over the typical days considered in the MILP model in 2050: (a) if solar-thermal systems are not incentivised; and (b) if a £3,000 investment incentive is implemented.

\section{Conclusions}

This paper presents and investigation of the potential of different solar-thermal heating systems in the UK. A range of different collectors available on the market were surveyed and four representative ones were selected for further investigation. In a typically sized system with a collector area of $4 \mathrm{~m}^{2}$ and a 160-L hot water storage tank, all collectors are capable of supplying a significant share of the annual domestic hot water demand of a typical household. With heat output of up to $580 \mathrm{~W} / \mathrm{m}^{2}$, solar fractions of up to $70 \%$ are achieved. To assess the potential for water and space heating, a parametric study of systems with varying collector areas and tank sizes was performed. Systems with collector areas larger than $10 \mathrm{~m}^{2}$ are able to supply more than $80 \%$ of the annual DHW demand, and values close to $100 \%$ are possible with even larger $\left(>15 \mathrm{~m}^{2}\right)$ collectors. Water tanks of about 150 to $200 \mathrm{~L}$ provide much value to the system but increasing the tank size any further does not increase the solar fraction. In the space heating case, systems struggle to reach solar fraction larger than $55 \%$ even if collectors and storage tanks are excessively large $\left(50 \mathrm{~m}^{2}\right.$ and $\left.>1000 \mathrm{~L}\right)$. It appears that seasonal storage with water tanks at household scale is impractical. An analysis of the specific costs shows that solar DHW heating systems with collector sizes of 4 to $8 \mathrm{~m}^{2}$ and tank sizes of 100 to $200 \mathrm{~L}$ provide the best annualised investment cost to annual heat output ratio. 
An analysis of solar-thermal systems in a heating sector decarbonisation model shows that solar-assisted heating struggles to be competitive with hydrogen or heat pumps under default cost assumptions. However, if the installation of solar collectors is incentivised, they can provide significant system value by reducing the demand for carbon-neutral hydrogen or electricity. An investment incentive of $£ 3,000$ leads to over $150 \mathrm{GW}$ of solar-thermal capacity to be deployed by 2050 , which leads to $240 \mathrm{TWh}$ of annual hydrogen savings, while and electricity demand of $90 \mathrm{TWh}$ is added due to electric backup technologies. In future, solar-thermal systems may benefit from cost reductions due to learning rates and scaling effects. These effects are however not modelled in this work and will have to be investigated further.

Future work aims to further investigate the solar-thermal potential in a whole-system context, considering different systems and multi-day energy storage. Learning rates for technologies may be included to model future costs more accurately. Another step is to include electricity and hydrogen generation in the model in order to quantify potential savings due to reduced demands. It is also planned to assess innovative technologies such as combined PV and thermal and solar-assisted heat pumps, which can potential be sustainable, cost-competitive heat and electricity generation technologies.

\section{Acknowledgements}

This work was supported by the UK Engineering and Physical Sciences Research Council (EPSRC) [grant numbers EP/R045518/1 and EP/P004709/1]. Data supporting this publication can be obtained on request from cep-lab@imperial.ac.uk.

\section{Nomenclature}

Abbreviations
ASHP air-source heat pump
CCC Committee on Climate Change
DHW domestic hot water
ETC evacuated-tube collector
FPC flat-plate collector
HP high performance
LC low cost
MILP mixed-integer linear programming

\section{Latin symbols}

$C_{1}, c_{2}$ heat loss coefficients

I irradiance, $\mathrm{W} / \mathrm{m}^{2}$

$T$ temperature, $\mathrm{K}$

\section{Greek symbols}

$\eta \quad$ efficiency

$\eta_{0} \quad$ optical efficiency

\section{Subscripts and superscripts}

col collector

amb ambient

solar solar

\section{References}

[1] Committee on Climate Change, "Heat in UK buildings today," 2016 - Available at: https://www.theccc.org.uk/wp-content/uploads/2017/01/Annex-2-Heat-in-UK-Buildings-TodayCommitteeon-Climate-Change-October-2016.pdf .

[2] F. Liu, L. Zheng, and R. Zhang, "Emissions and thermal efficiency for premixed burners in a condensing gas boiler" Energy, vol. 202, 2020, doi: 10.1016/j.energy.2020.117449.

[3] Department for Business Energy \& Industrial Strategy, "Final UK greenhouse gas emissions national statistics: 1990 to 2019." 2021 - Available at: https://www.gov.uk/government/statistics/final-ukgreenhouse-gas-emissions-national-statistics-1990-to-2019.

[4] Department for Business Energy \& Industrial Strategy, "2019 UK greenhouse gas emissions, provisional figures" 2020 - Available at: https://assets.publishing.service.gov.uk/government/uploads/ 
system/uploads/attachment data/file/875485/2019 UK greenhouse gas emissions provisional figures statistical release.pdf .

[5] Committee on Climate Change, "The Sixth Carbon Budget: The UK's path to Net Zero" London, 2020 Available at: https://www.theccc.org.uk/publication/sixth-carbon-budget/ .

[6] National Grid, "Future Energy Scenarios" 2020 - Available at: https://www.nationalgrideso.com/futureenergy/future-energy-scenarios/fes-2020-documents .

[7] D. Quiggin and R. Buswell, "The implications of heat electrification on national electrical supply-demand balance under published 2050 energy scenarios" Energy, vol. 98, pp. 253-270, 2016, doi: 10.1016/j.energy.2015.11.060.

[8] N. Eyre and P. Baruah, "Uncertainties in future energy demand in UK residential heating" Energy Policy, vol. 87, pp. 641-653, 2015, doi: 10.1016/j.enpol.2014.12.030.

[9] X. Zhang, G. Strbac, F. Teng, and P. Djapic, "Economic assessment of alternative heat decarbonisation strategies through coordinated operation with electricity system - UK case study" Appl. Energy, vol. 222, no. January, pp. 79-91, 2018, doi: 10.1016/j.apenergy.2018.03.140.

[10] N. Sunny, N. Mac Dowell, and N. Shah, "What is needed to deliver carbon-neutral heat using hydrogen and CCS?" Energy Environ. Sci., 2020, doi: 10.1039/D0EE02016H.

[11] D. Tschopp, Z. Tian, M. Berberich, J. Fan, B. Perers, and S. Furbo, "Large-scale solar thermal systems in leading countries: A review and comparative study of Denmark, China, Germany and Austria" Appl. Energy, vol. 270, no. January, p. 114997, 2020, doi: 10.1016/j.apenergy.2020.114997.

[12] Z. Tian et al., "Large-scale solar district heating plants in Danish smart thermal grid: Developments and recent trends" Energy Convers. Manag., vol. 189, no. October 2018, pp. 67-80, 2019, doi: 10.1016/j.enconman.2019.03.071.

[13] R. Renaldi and D. Friedrich, "Techno-economic analysis of a solar district heating system with seasonal thermal storage in the UK" Appl. Energy, vol. 236, no. October 2018, pp. 388-400, 2019, doi: 10.1016/j.apenergy.2018.11.030.

[14] Z. Ma, H. Bao, and A. P. Roskilly, "Feasibility study of seasonal solar thermal energy storage in domestic dwellings in the UK" Sol. Energy, vol. 162, no. July 2017, pp. 489-499, 2018, doi: 10.1016/j.solener.2018.01.013.

[15] M. Herrando, C. N. Markides, and K. Hellgardt, "A UK-based assessment of hybrid PV and solar-thermal systems for domestic heating and power: System performance" Appl. Energy, vol. 122, pp. 288-309, 2014, doi: 10.1016/j.apenergy.2014.01.061.

[16] M. Herrando and C. N. Markides, "Hybrid PV and solar-thermal systems for domestic heat and power provision in the UK: Techno-economic considerations" Appl. Energy, vol. 161, pp. 512-532, 2016, doi: 10.1016/j.apenergy.2015.09.025.

[17] B. Greening and A. Azapagic, "Domestic solar thermal water heating: A sustainable option for the UK?" Renew. Energy, vol. 63, pp. 23-36, 2014, doi: 10.1016/j.renene.2013.07.048.

[18] M. Z. Jacobson and V. Jadhav, "World estimates of PV optimal tilt angles and ratios of sunlight incident upon tilted and tracked PV panels relative to horizontal panels" Sol. Energy, vol. 169, no. April, pp. 5566, 2018, doi: 10.1016/j.solener.2018.04.030.

[19] C. D. Lloyd, G. Catney, P. Williamson, and N. Bearman, "Population Change in Britain" Liverpool, 2017. doi: 10.1111/j.0028-8292.1973.tb00505.x.

[20] European Commission, "Photovoltaic Geographical Information System (PVGIS)" 2020 - Available at: https://ec.europa.eu/jrc/en/pvgis [accessed 07.03.2021].

[21] R. Sansom, "Decarbonising low grade heat for low carbon future" Imperial College London, 2014.

[22] Department for Business Energy \& Industrial Strategy, "Cambridge Housing Model and user guide" 2015 - Available at: https://www.gov.uk/government/publications/cambridge-housing-model-and-user-guide [accessed 10.02.2021].

[23] G. Davies, G. Maidment, A. Paurine, P. Rutter, T. Evans, and R. Tozer, "Large scale cooling systems using mains water" in Refrigeration Science and Technology, 2016, pp. 1076-1083, doi: 10.18462/iir.gl.2016.1183.

[24] A. V. Olympios, M. Mersch, P. Sapin, A. M. Pantaleo, and C. N. Markides, "Library of price and performance data of domestic and commercial technologies for low-carbon energy systems" (Version 1) 2021 [Data set]. Zenodo, doi: 10.5281/zenodo.4692649.

[25] C. F. Heuberger, I. Staffell, N. Shah, and N. Mac Dowell, "A systems approach to quantifying the value of power generation and energy storage technologies in future electricity networks" Comput. Chem. Eng., vol. 107, pp. 247-256, Dec. 2017, doi: 10.1016/j.compchemeng.2017.05.012. 
[26] C. F. Heuberger, E. S. Rubin, I. Staffell, N. Shah, and N. Mac Dowell, "Power capacity expansion planning considering endogenous technology cost learning" Appl. Energy, vol. 204, no. August, pp. 831-845, 2017, doi: 10.1016/j.apenergy.2017.07.075.

[27] Office for National Statistics, "Families and households in the UK: 2020" 2021 - Available at: https://www.ons.gov.uk/peoplepopulationandcommunity/birthsdeathsandmarriages/families/bulletins/fam iliesandhouseholds/2020 [accessed 08.03.2021].

[28] S. D. Watson, K. J. Lomas, and R. A. Buswell, "Decarbonising domestic heating: What is the peak GB demand?" Energy Policy, vol. 126, pp. 533-544, 2019, doi: 10.1016/j.enpol.2018.11.001.

[29] Department for Business Energy \& Industrial Strategy, "Cost of installing heating measures in domestic properties" 2020 - Available at: https://www.gov.uk/government/publications/cost-of-installing-heatingmeasures-in-domestic-properties .

[30] The GreenAge, "Is solar thermal worth it?" 2020 - Available at: https://www.thegreenage.co.uk/is-solarthermal-worth-it/ [08.03.2021].

[31] Evergreen Energy, "How much to solar thermal panels cost?" 2019 - Available at: https://www.evergreenenergy.co.uk/solar-thermal-panels/how-much-do-solar-thermal-panels-cost/ [accessed 08.03.2021].

[32] Local Heroes, "How much does a boiler service cost?" 2021 - Available at: https://www.localheroes.com/advice/how-much-boiler-service [accessed 08.03.2021].

[33] Mitsubishi Electric Europe, "Service \& Maintenance Plans for Homeowners" 2016 - Available at: https://les.mitsubishielectric.co.uk/assets/Uploads/cbce9e3316/MELSMART-SERV-MAINTHOMEOWNER.pdf [accessed 08.03.2021].

[34] Westward Energy Services, "Solar Thermal Servicing \& Maintenance" 2018 - Available at: https://www.westwardservices.com/private-home-heating-services/solar-thermal-servicing-andmaintenance/ [accessed 08.03.2021].

[35] A. V. Olympios, A. M. Pantaleo, P. Sapin, and C. N. Markides, "On the value of combined heat and power (CHP) systems and heat pumps in centralised and distributed heating systems: Lessons from multi-fidelity modelling approaches" Appl. Energy, vol. 274, p. 115261, Sep. 2020, doi: 10.1016/j.apenergy.2020.115261.

[36] Boiler Guide, "Hydrogen Boilers: An Alternative to Gas Central Heating?" 2020 - Available at: https://www. boilerguide.co.uk/articles/hydrogen-boilers-alternative-gas-central-heating [accessed 08.03.2021].

[37] Element Energy Ltd., "Hydrogen supply chain evidence base" 2018 - Available at: https://assets.publishing.service.gov.uk/government/uploads/system/uploads/attachment data/file/7604 79/H2 supply chain evidence - publication version.pdf.

[38] Statista, "Electricity prices for households in the United Kingdom (UK) from 2010 to 2020, semi-annually" 2020 - Available at: https://www.statista.com/statistics/418126/electricity-prices-for-households-in-the-uk/ [accessed 08.03.2021].

[39] Department for Business Energy \& Industrial Strategy, "Greenhouse gas reporting: conversion factors 2019" 2019 - Available at: https://www.gov.uk/government/publications/greenhouse-gas-reportingconversion-factors-2019.

[40] Statista, "Household natural gas prices in the United Kingdom from 1995 to 2019" 2020 - Available at: https://www.statista.com/statistics/1049319/household-natural-gas-price-united-kingdom/ [accessed 08.03.2021].

[41] Department for Business Energy \& Industrial Strategy and Prime Minister's Office, "The Ten Point Plan for a Green Industrial Revolution." 2020 - Available at: https://www.gov.uk/government/publications/theten-point-plan-for-a-green-industrial-revolution/title .

[42] Statista, "Annual amount of heat pumps in operation in the United Kingdom (UK) from 2013 to 2019" 2020 - Available at: https://www.statista.com/statistics/740491/heat-pumps-in-operation-uk/ [accessed 11.03.2021].

[43] Bundesverband Wärmepumpe e.V., "Positives Signal für den Klimaschutz: 40 Prozent Wachstum bei Wärmepumpen" 2021 - Available at: https://www.waermepumpe.de/presse/pressemitteilungen/details/ positives-signal-fuer-den-klimaschutz-40-prozent-wachstum-bei-waermepumpen/\#content [accessed 11.03.2021].

[44] EurObserv'ER, "Solar thermal and concentrated solar power barometers" 2019 - Available at: https://www.eurobserv-er.org/pdf/solar-thermal-and-csp-barometer-2019-en/ .

[45] Department for Business Energy \& Industrial Strategy, "Digest of UK Energy Statistics (DUKES) 2019." 2019 - Available at: https://www.gov.uk/government/statistics/digest-of-uk-energy-statistics-dukes-2019 .

[46] Ofgem, "Domestic Renewable Heat Incentive (RHI)" 2020 - Available at: https://www.ofgem.gov.uk/environmental-programmes/domestic-rhi [accessed 11.03.2021]. 